\title{
Plasma Treatment of Polyamide Fabric Surface by Hybrid Corona-Dielectric Barrier Discharge: Material Characterization and Dyeing/Washing Processes
}

\author{
Fernando Gasi ${ }^{a *}$, Gilberto Petraconi ${ }^{b}$, Edison Bittencourt ${ }^{b}$, Sérgio Ricardo Lourenço ${ }^{a}$, Alonso
}

Hernan Ricci Castro ${ }^{b}$, Felipe de Souza Miranda ${ }^{\mathbb{D}}$, Alexei Mikhailovich Essiptchouk ${ }^{c}$, Larissa

Nascimento $^{b}$, André Petraconi ${ }^{b}$, Mariana Amorim Fraga $^{d}$, Rodrigo Savio Pessoa ${ }^{b}$

${ }^{a}$ Universidade Federal do ABC (UFABC), Centro de Engenharia, Modelagem e Ciências Sociais Aplicadas, 09210-170, São Bernardo do Campo, SP, Brasil.

${ }^{b}$ Centro de Ciência e Tecnologia de Plasmas e Materiais (PlasMat), 12228-900, São José dos Campos, SP, Brasil.

${ }^{c}$ Universidade Estadual Paulista (UNESP), Instituto de Ciência e Tecnologia, 12247-004, São José dos

Campos, SP, Brasil.

${ }^{d}$ Instituto de Ciência e Tecnologia, Universidade Federal de São Paulo, 12231-280, São José dos

Campos, SP, Brasil.

Received: March 19, 2019; Revised: July 05, 2019; Accepted: October 16, 2019

In this study, the hybrid corona-dielectric barrier discharge plasma treatment was employed to modify the physical, chemical and morphological characteristics of a half-knitted fabric composed of $92 \%$ polyamide 6.6 and $8 \%$ elastane (PA). These properties of the fabric were evaluated by the water contact angle, $\mathrm{x}$-ray diffraction, infrared spectroscopy, scanning electron microscopy and atomic force microscopy techniques. In addition, the dyeing and washing processes were also investigated. A significant reduction of the contact angle was observed for plasma-treated PA. Infrared spectroscopy analyses indicated that $\mathrm{C}-\mathrm{H}, \mathrm{N}-\mathrm{H}$, and $\mathrm{N}-\mathrm{O}$ groups in PA increased after plasma treatment, explaining the improved coloring strength for the plasma-treated samples when dyed with reactive and acid dyes. A better fixation of dye was also observed after the atmospheric plasma treatment. Furthermore, dyeing with a basic and acid dye caused the dyeability increases for the plasma-treated sample compared with the untreated sample.

Keywords: Corona, dielectric barrier discharge, textile, polyamide, surface treatment.

\section{Introduction}

Synthetic fabrics are very useful in the textile industry. These fabrics have high strength, elasticity, lightness, fewer wrinkles, and fast-drying compared to cotton ${ }^{1}$. The chemical process is the most common way of improving the surface characteristics of fabrics. But in recent years, different alternative eco-friendly processes are being tried, seeking to decrease the use of chemicals ${ }^{2-4}$. Between these processes, advanced plasma processing has been highlighting as a dry treatment and green technology that allows modifications at the micro/nanoscale of heatsensitive materials such as textiles ${ }^{4-6}$. The use of plasma improves the performance of textile material preparation and dyeing systems, thus reducing the consumption of dyes and, consequently, the environmental impacts caused by the dyeing process ${ }^{4}$. Thus, plasma technology can be considered a green technology because reduces energy and water consumption ${ }^{4,6,7}$. As result, non-thermal plasmas have been increasingly used to improve textile surface properties, such as wettability, surface adhesion, and printing capacity, without increasing its temperature and, consequently, maintaining unaffected the intrinsic properties of the bulk material ${ }^{4,6,8,9}$.
There are three main types of non-thermal atmospheric plasmas applied to textiles processing namely corona discharge ${ }^{10}$, dielectric barrier discharge (DBD) ${ }^{11,12}$, and atmospheric pressure plasma jets (APPJ) ${ }^{13,14}$.Among them, DBD is the most commonly used geometry. The DBD is a non-thermal plasma consisting of the air ionization at atmospheric pressure, generated by a high voltage and low-frequency source, and when applied to textile processing modifies the surface properties of natural and synthetic fibers by several forms of interactions, such as electrons and ions, radicals, UV radiation, among others ${ }^{9}$. As a consequence of the interactions between plasma and textile substrate, some surface effects may be observed such as surface etching, chain scission, polymerization, creation of polar groups and surface roughness ${ }^{9,15}$. In addition, these treatment effects have shown to be susceptible to the operational parameters such as electrode geometry, gas type, and flow, and dosage, as well as the characteristics of the surface to be treated. For example, the wettability of a textile can be increased with the use of oxygen-based plasmas, while the hydrophobic behavior can be increased by using fluorocarbon-based plasmas ${ }^{14}$. Therefore, a better understanding of the effect of the process parameters on the final characteristics of the DBD plasmatreated textile material is of interest, since there are few results published in the literature. 
Among the synthetic fabrics, polyamide (PA) is one of the most commonly used textile materials having the best abrasion resistance and is widely applied for clothes fabrics, package paper, carpets, and ropes. However, PA fabrics are alkali resistant and prone to the acidic solution ${ }^{16}$. Acid dyes are the most common in use for PA dyeing, but some problems are very well known, as difficulties to manage uniformity and fastness ${ }^{16}$. The required $\mathrm{pH}$ to achieve good exhaustion of dye in the fiber must be carefully controlled and sometimes is excessively low. To achieve better dyeing results in PA fibers some trials are reported in the literature using new techniques for structural changes, being irradiation through lasers ${ }^{17}$ or plasmas ${ }^{9,16}$ presented as a promising solution.

In this article, we report the effect of a commercial hybrid corona-DBD plasma on the properties of polyamide 6.6 knitted fabric using the following characterization techniques: water contact angle, $\mathrm{x}$-ray diffraction, infrared spectroscopy, scanning electron microscopy and atomic force microscopy. The dyeing/washing process of the treated samples was also evaluated.

\section{Materials and Methods}

\subsection{Fabric material specification}

Here, a half-knitted fabric composed of $92 \%$ polyamide 6.6 (PA 6.6, manufactured by Rhodia Solvay) and 8\% elastane (Lycra brand, manufactured by Invista) was utilized in the experiments. This knitted fabric was produced in fine machinery ( 38 needles per inch) with a surface mass of $180 \mathrm{~g} / \mathrm{m}^{2}$. The size of the samples used was $25 \times 60 \mathrm{~cm}^{2}$. Prior to dyeing, the fabric was washed to remove wax, dirt impurities and oils in order to improve dyeing uptake and evenness. Thus, the knit fabric was treated with $1.0 \mathrm{~g} / \mathrm{L}$ of detergent and $1.0 \mathrm{~g} / \mathrm{L}$ of sodium carbonate (soda ash) and then heated during $20 \mathrm{~min}$ at a temperature of about $60{ }^{\circ} \mathrm{C}$. This process is usually called ready-to-dye (RTD). The dyes were manufactured and supplied by CHT Brazil Chemical.

\subsection{Plasma treatment}

The plasma treatment of the samples was carried out in a commercial hybrid corona-DBD plasma system (PLASMA LABO, Arioli, Italy). Details about the corona inducing dielectric barrier discharge can be found in ${ }^{18}$. Figure 1 shows the schematic diagram of the plasma reactor. The plasma is generated between a cylindrical grounded electrode covered by a silicone dielectric layer, where the sample is positioned and a set of high voltage electrodes that are placed on two sides of the grounded electrode. In this system, the high-frequency utilized $(50 \mathrm{kHz})$ power supply, which can operate with different discharge power, operating frequency, and duty cycle.
Here, we used the plasma dosage of 1333 W.min $/ \mathrm{m}^{-2}$ (number of passages $=4$ and exposure time during each passage $=2 \mathrm{~s}$ ). The sample was vertically positioned between the electrodes and the air plasma was applied. After the plasma treatment, the sample was kept in vacuum-sealed plastic bags for further characterization and comparison with the untreated (control) sample.

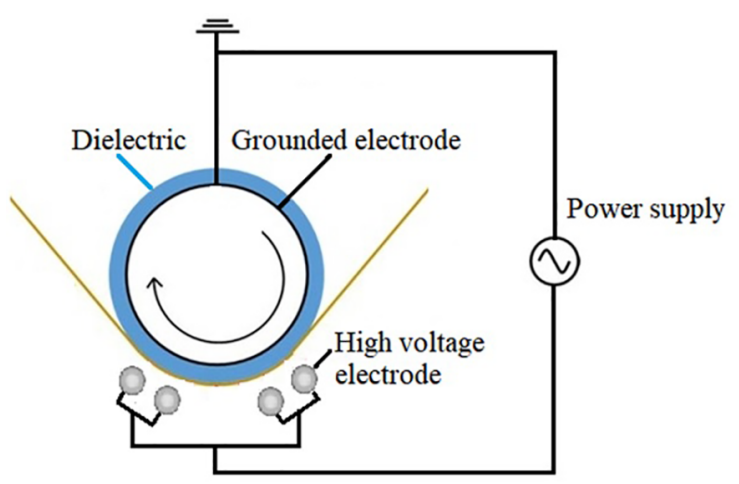

Figure 1. Schematic diagram of PLASMA LABO equipment.

\subsection{Material characterization}

The water contact angle (WCA) measurements were performed to evaluate the plasma effects on control and plasma-treated samples. Properties of the surface were evaluated by the sessile drop method with a goniometer. This is a direct method to measure the contact angle where a distilled water drop was placed on the surface and the contact angle was measured. The equipment used was an FTA 1000 dynamic contact angle analyzer from First Ten Ångstroms Inc.

To identify the crystalline phases, X-ray diffraction (XRD) analyses were performed in a Bruker equipment, model D8 FOCUS. The monochromatic radiation $\mathrm{CuK} \alpha$ $(\lambda=1.5406 \AA, 40 \mathrm{kV}$ and $40 \mathrm{~mA}$ ) was performed with $\theta / 2 \theta$ geometry, in the $5^{\circ}<2 \theta<75^{\circ}$ interval, stepping angle of $0.03^{\circ}$ and point acquisition time of $1 \mathrm{~s}$.

To identify chemical changes generated by plasma treatment, the control, and treated samples were analyzed by Fourier transform infrared spectroscopy with attenuated total reflectance (FTIR-ATR), model Spotlight 400 from Perkin Elmer. Transmission spectra with 64 scans performed for each spectrum and resolution of $4 \mathrm{~cm}^{-1}$ were obtained. Samples were scanned from 450 to $2500 \mathrm{~cm}^{-1}$.

The techniques used to evaluate sample surfaces were Field Emission Scanning Electron Microscopy (FESEM) and Atomic Force Microscopy (AFM). FESEM was carried out in a Mira 3 from Tescan equipment and the micrographs were taken at $10 \mathrm{kV}$ with $100 \mathrm{x}$ to $10.000 \mathrm{x}$ magnitude. AFM analyses were performed in an Agilent equipment, model AFM/SPM, series 5500 operating in tapping mode. 


\subsection{Dyeing and washing test}

For sample dyeing, acid and reactive dyes were used according to the recipe described in Table 1. All experiments were performed in duplicate.

The evaluation of the washing solidity was performed according to the technical standard NBR -ISO-105-C06:2010 - color stability in domestic and commercial washing. The domestic washing solidity has been reached through spectrophotometer measurements performed by Datacolor $650{ }^{\circledR}$ equipment. This evaluation used the grayscale as a reference, with a variation from 1 to 5 , according to ABNT NBR ISO 105-A02 for color change (AT) and ABNT NBR ISO 105-A03 for color transfer (TC).

To evaluate the color change, spectrophotometry was used to quantify the color strength. This color strength is measured according to Kubelka-Munk Equation (eq. 1), which determines the value $(\mathrm{K} / \mathrm{S})$ based on CIE $\mathrm{L}^{*} \mathrm{a} * \mathrm{~b}^{*}$ coordinates, a three-dimensional system developed by Commission Internacionale de L'Eclairage (CIE) ${ }^{16}$.

$$
\frac{K}{S}=\frac{(1-R)^{2}}{2 R}
$$

where, $\mathrm{K}$ is the dye absorption coefficient, $\mathrm{S}$ the spreading coefficient and $\mathrm{R}$ the sample reflectance.

\section{Results and discussion}

\subsection{Contact angle analysis}

The time after exposure to the plasma is a determining factor for the wettability of the textile surface. Figure 2 shows the WCA versus aging time for plasma-treated samples. The initial value of the WCA of the PA fabric was about $120^{\circ}$, showing the hydrophobicity characteristic of this fiber. After plasma treatment, the WCA changed from 120 (non-treated) to $47^{\circ}$ (immediately after plasma treatment). This result may be attributed to the incorporation of polar groups onto the fabric surface ${ }^{16}$. It is possible to observe that after $30 \mathrm{~min}$ of the treatment the WCA increased to $66^{\circ}$, after $120 \mathrm{~min}$ the WCA increased to $83^{\circ}$ and, finally, after $25 \mathrm{~h}$ the WCA achieved the value of $105^{\circ}$. The hypotheses considered for this so-called hydrophobic recovery are based on subtle phenomena such as the dynamic behavior of the surface of polymers or mechanisms such as surface contamination and molecular dissociation ${ }^{9,19}$.
Oliveira et al. also observed WCA reduction after plasma treatment of three different types of commercial polyamide fabrics treated. They used a semi-industrial prototype DBD plasma system and the maximum WCA reduction observed after plasma treatment was of $23.3^{\circ}{ }^{9}$. An interesting point in their results is that at a dosage of $2500 \mathrm{~W} \cdot \mathrm{min} . \mathrm{m}^{-2}$, it was possible to maintain a lower WCA for 30 days.

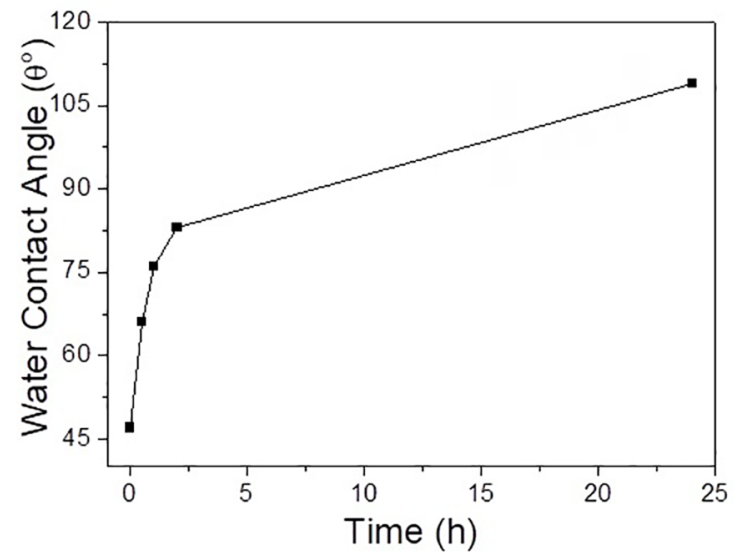

Figure 2. Water contact angle versus time.

\subsection{Chemical and physical characterization}

FTIR-ATR spectroscopy was used to characterize the functional groups and detect the chemical changes after the plasma treatment.

The FTIR spectra of untreated and plasma-treated PA fabric are exhibited in Figure 3. In this spectrum, the amide bands of the PA appear at 1630 and $1532 \mathrm{~cm}^{-1}$. Also, the peaks between 1200 and $900 \mathrm{~cm}^{-1}$ can be ascribed to the skeletal aliphatic $\mathrm{C}-\mathrm{C}$ and aliphatic $\mathrm{C}-\mathrm{H}$ rocking of the polyamide ${ }^{20}$.

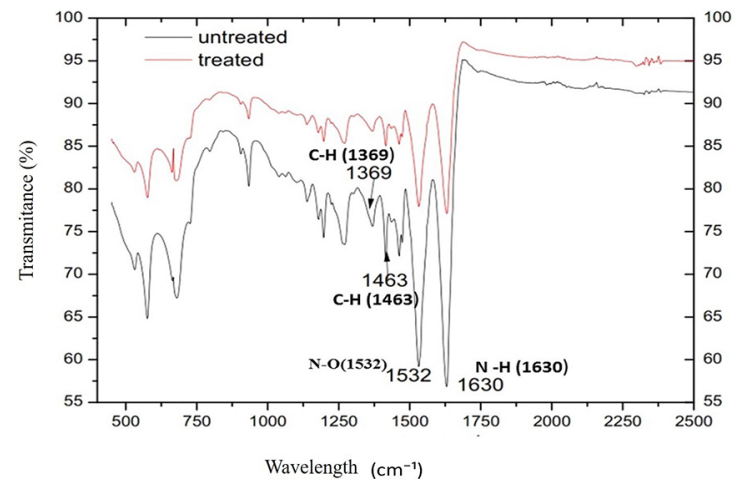

Figure 3. FTIR spectra of control and plasma treated sample.

Table 1. Recipe of dyeing process performed in this work.

\begin{tabular}{cccc}
\hline Item & Description & Dyeing with acid dye & Dyeing with reactive dye \\
\hline A & Equalizing agent & Sarabid IDP $-1.0 \%$ & Sarabid IDP $-1.0 \%$ \\
A & Dye & Bemacid E-TL-RED & Bezaktiv- S2G-BLUE \\
B & Ph regulator & Neutracid NVM & Neutracid NVM \\
C & Rinsing time in running water & 10 min & 10 min \\
\hline
\end{tabular}


The spectrum of the plasma-treated PA fabric is almost similar to the spectrum of the untreated one. The difference is in the increase of groups corresponding to $\mathrm{C}-\mathrm{H}, \mathrm{N}-\mathrm{H}$ and $\mathrm{N}-\mathrm{O}$. This increase provides a greater affinity for dyeing, thereby improving the efficiency of the dye.

Figure 4 illustrates the $x$-ray diffractograms of the samples analyzed. The results evidence the presence of crystalline phases with well-defined peaks at $2 \theta$ values $14.1^{\circ}, 16.9^{\circ}$, and $25.5^{\circ}$. The difference between untreated samples and treated samples is in the peak intensity, showing that the plasma treatment increased PA fabric crystallinity. Shalaby et al. observed similar results during studies of surface activation of Nylon-6 fabrics by DBD plasma ${ }^{21}$.

\subsection{Surface characterization}

Surface analyses using the FESEM technique showed that plasma treatment promoted a change in the morphology of the PA fabric (Figure 5). As can be seen in Fig. 5b, the topography of the fiber was altered after plasma treatment in trough the increase of surface roughness induced by the plasma etching process ${ }^{9}$.

In order to better visualize the SEM results, the topographic parameters of the surfaces of the samples were inferred from atomic force microscopy (AFM) analysis. As observed in Figure 6, the comparison between AFM images of the untreated and treated samples allows us to notice that the air
DBD treatment induced the formation of valleys whose depth and size are associated with the interaction of plasma with the surface. Table 2 presents the roughness values measured from AFM images of the investigated samples. The values presented in Table 2 are the respective averages of roughness along the 4 lines drawn. In this table, it can be noted that the highest roughness is for the plasma-treated sample for all amplitude parameters. For example, the quadratic roughness, $\mathrm{R}_{\mathrm{q}}$, of the treated fabric is 1.67 times higher than that of the untreated fabric.

The increased roughness, as well as the chemical changes, causes a reduction of the contact angle, contributing to increasing the hydrophilic capacity of samples previously treated with plasma.

\subsection{Dyeing and washing assays}

The evaluation of dyed pristine and plasma-treated fabrics was performed based on the following analyses: determination of coloring strength and domestic washing solidity.

The results of the coloring strength analysis that were obtained with the use of spectrophotometry technique are shown in Tables 3 and 4 for BEZAKTIV-S2G-BLUE dye and BEMACID E-TL-RED dye, respectively. Variations $(\Delta)$ are the differences between the values obtained in the samples analyzed (plasma-treated) and the pattern established (untreated).

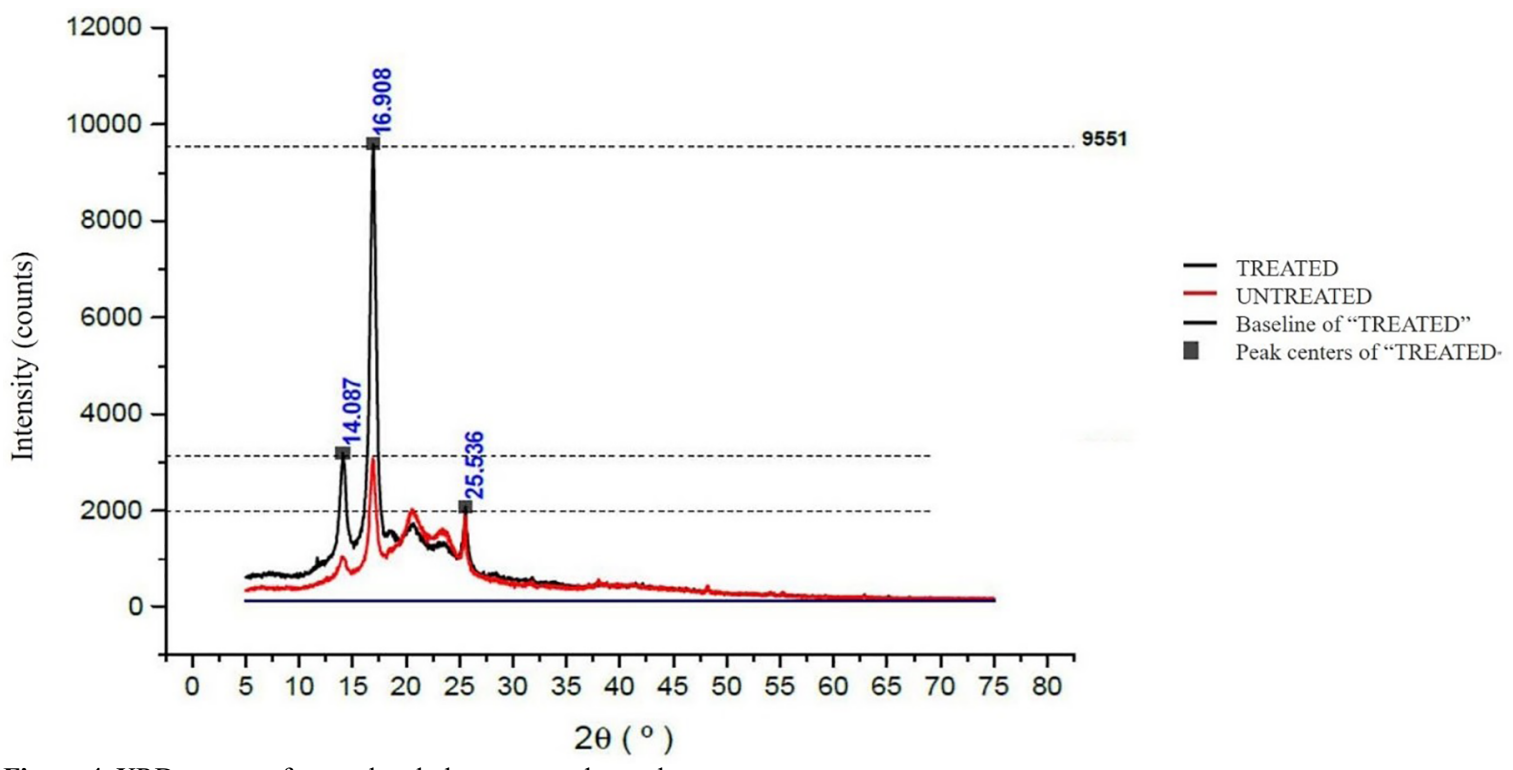

Figure 4. XRD spectra of control and plasma treated sample.

Table 2. Control and plasma treated surface roughness. Where, $R_{a}$ : average roughness; $R_{q}$ : quadratic roughness; $R_{t}$ : total roughness; $\mathrm{R}_{\mathrm{tm}}$ : average total roughness; $\mathrm{R}_{\mathrm{v}}$ : valley maximum depth; $\mathrm{R}_{\mathrm{p}}$ : peak maximum height.

\begin{tabular}{lcccccc}
\hline \multicolumn{7}{c}{ Roughness amplitude parameters } \\
\hline Sample & $\mathrm{Ra}(\mathrm{nm})$ & $\mathrm{Rq}(\mathrm{nm})$ & $\mathrm{Rt}(\mathrm{nm})$ & $\mathrm{Rtm}(\mathrm{nm})$ & $\mathrm{Rv}(\mathrm{nm})$ & $\mathrm{Rp}(\mathrm{nm})$ \\
\hline Untreated & 0.007 & 0.009 & 0.046 & 0.030 & 0.024 & 0.022 \\
\hline Plasma treated & 0.013 & 0.015 & 0.103 & 0.070 & 0.045 & 0.060 \\
\hline
\end{tabular}



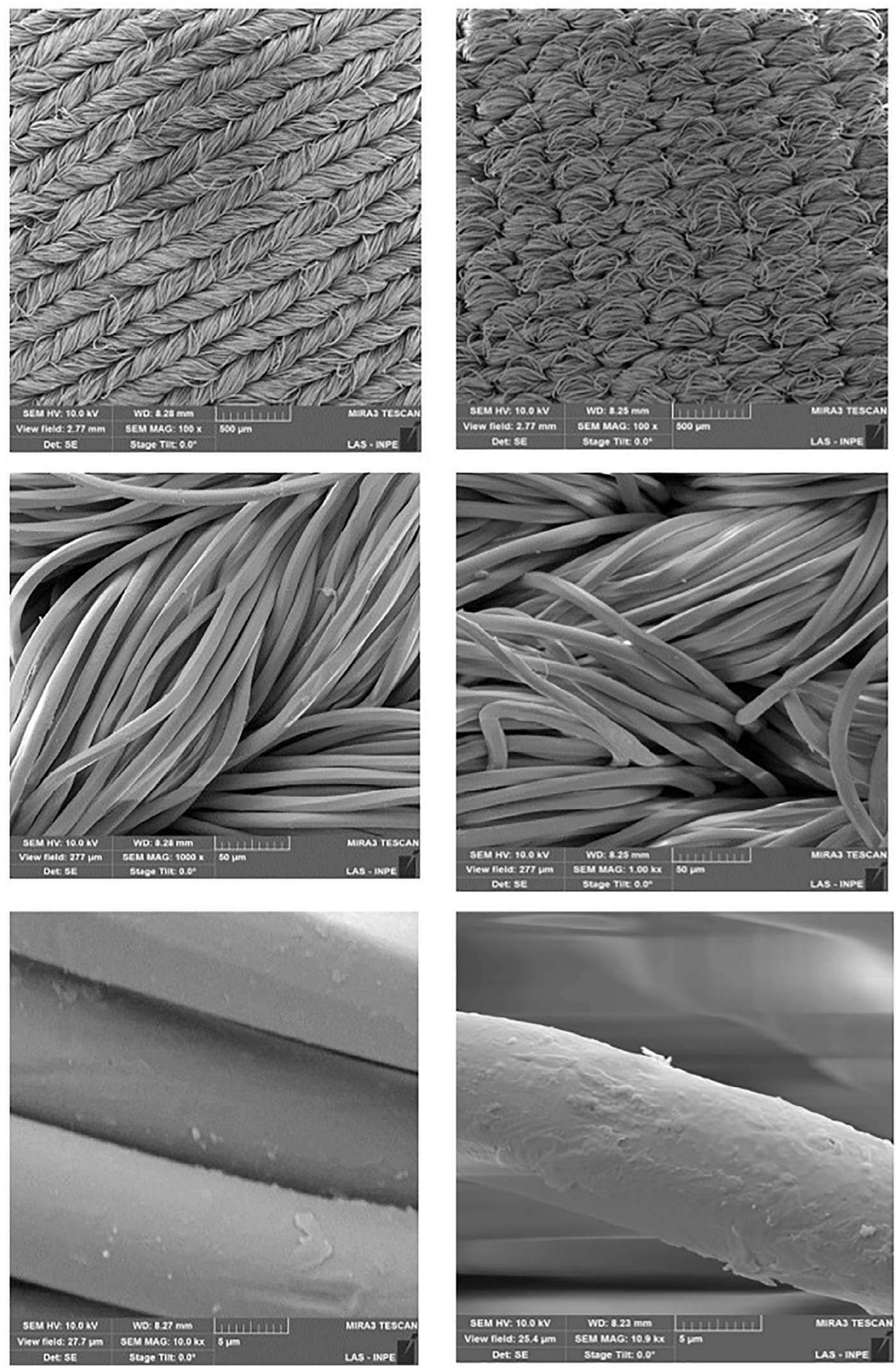

(a)

(b)

Figure 5. SEM micrographs of PA fabric in different magnitudes for (a) control sample and (b) plasma-treated sample. 
(a)

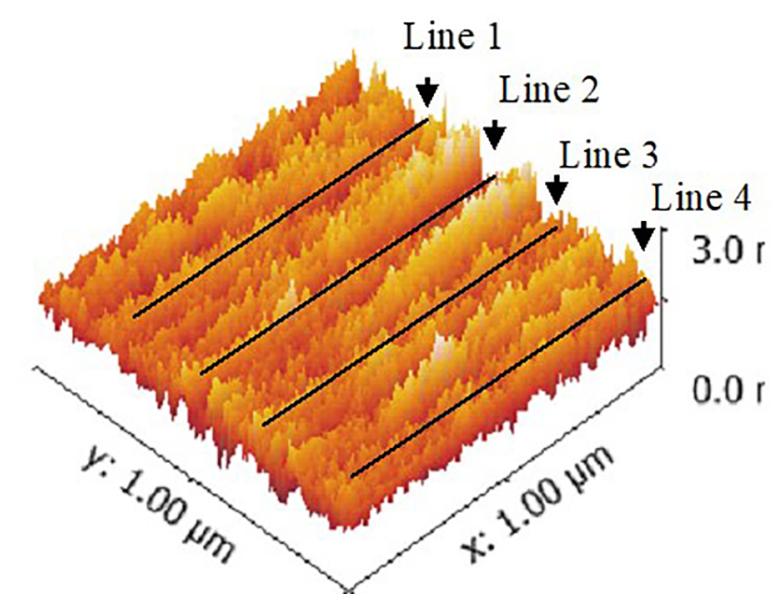

(b)

Figure 6. AFM images of (a) non-treated and (b) plasma-treated PA fabric surface.

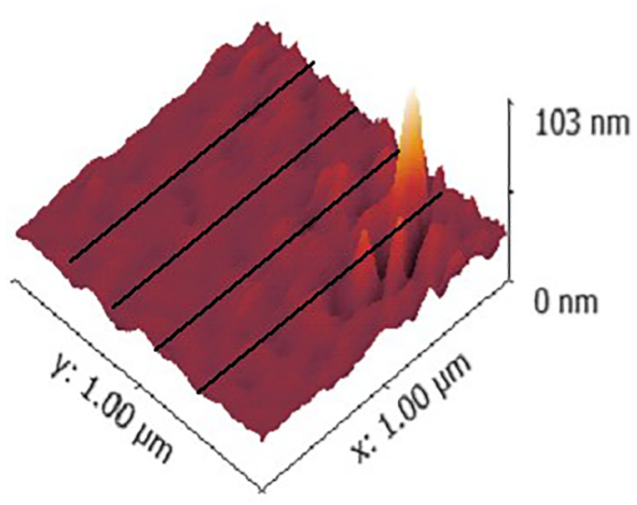

Table 3. Results - BEZAKTIV- S2G- BLUE dye. Note: CIE L*a*b coordinates*

\begin{tabular}{lllllc}
\hline \multicolumn{7}{c}{$1^{\text {st }}$ Reading } \\
\hline Sample & $\Delta \mathrm{L}^{*}$ & $\Delta \mathrm{a}^{*}$ & $\Delta \mathrm{b}^{*}$ & $\Delta \mathrm{E}^{*}$ & Coloring strength $(\mathrm{K} / \mathrm{S})$ \\
\hline $\mathrm{B}_{1}$ & -6.25 & -0.25 & -4.73 & 7.84 & $174.14 \%$ \\
\hline Sample & \multicolumn{5}{c}{$2^{\text {nd }}$ Reading } \\
\hline $\mathrm{B}_{2}$ & $\Delta \mathrm{L}^{*}$ & $\Delta \mathrm{a}^{*}$ & $\Delta \mathrm{b}^{*}$ & $\Delta \mathrm{E}^{*}$ & Coloring strength (K/S) \\
\hline
\end{tabular}

Table 4. Results - BEMACID E-TL-RED dye. Note: CIE L*a*b coordinates*. Variations $(\Delta)$ are the differences between the values obtained in the samples analyzed (plasma-treated) and the pattern established (untreated).

\begin{tabular}{cccccc}
\hline \multicolumn{5}{c}{$1^{\text {st }}$ Reading } \\
\hline Sample & $\Delta \mathrm{L}^{*}$ & $\Delta \mathrm{a}^{*}$ & $\Delta \mathrm{b}^{*}$ & $\Delta \mathrm{E}^{*}$ & Coloring strength $(\mathrm{K} / \mathrm{S})$ \\
\hline $\mathrm{B}_{1}$ & -4.06 & 1.57 & 3.39 & 5.52 & $149.76 \%$ \\
\hline Sample & $\Delta \mathrm{L}^{*}$ & $\Delta \mathrm{a}^{*}$ & $2^{\text {nd }}$ Reading & \\
\hline $\mathrm{B}_{2}$ & -4.21 & 1.67 & $\Delta \mathrm{b}^{*}$ & $\Delta \mathrm{E}^{*}$ & Coloring strength (K/S) \\
\hline
\end{tabular}

Figures $7 \mathrm{a}$ and $7 \mathrm{c}$ present the colorimetric coordinates for blue and red dyed samples, respectively. Figures $7 \mathrm{~b}$ and $7 \mathrm{~d}$ present the reflectance analysis of the blue and red dyed samples, respectively. From colorimetric coordinates, it was possible to identify that after dyeing, the plasma-treated samples had an increase in the coloring strength for both dyes evaluated when compared with the untreated dyed sample. Complementing the color location analyses, the radar and reflection line charts are tools that identify the colorimetric coordinates ( $\mathrm{L}^{*}, \mathrm{a}^{*}$, and $\mathrm{b}^{*}$ ), thus allowing us to know how effective the dyeing was.

Figure 8 illustrates the investigated samples dyed with the red and blue dyes, respectively. It is possible to visually identify that plasma treatment allowed a better color fixation for both dyes used.

For better visualization of the analytical results for polyamide samples, Tables 5 and 6 are intended to relate the values of solidity degree for BEZAKTIV-S2G-BLUE and BEMACID E-TL-RED dyes, respectively. Plasmatreated fabrics and dyed with BEZAKTIV- S2G-BLUE dye kept the color change degree in the grayscale of the untreated fabric. These results refer to domestic washing solidity for AC and TC, corresponding to a good solidity. Plasma-treated fabrics and dyed with BEMACID E-TLRED dye kept the domestic washing solidity of the untreated fabric for AC. 


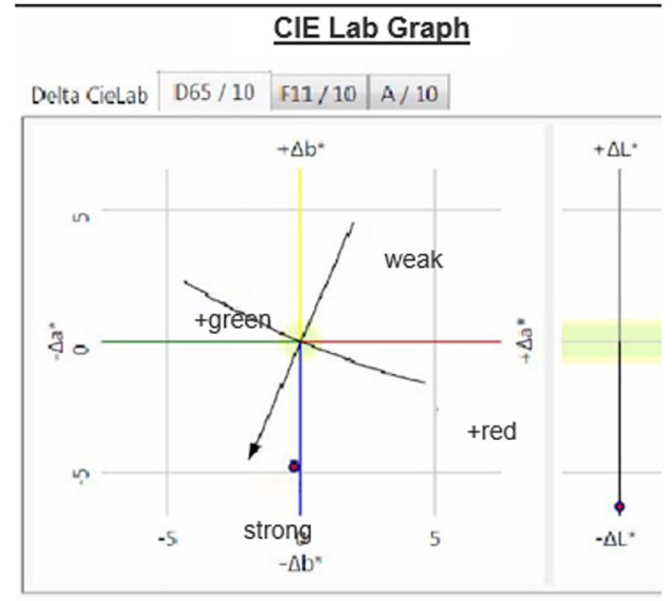

(a)

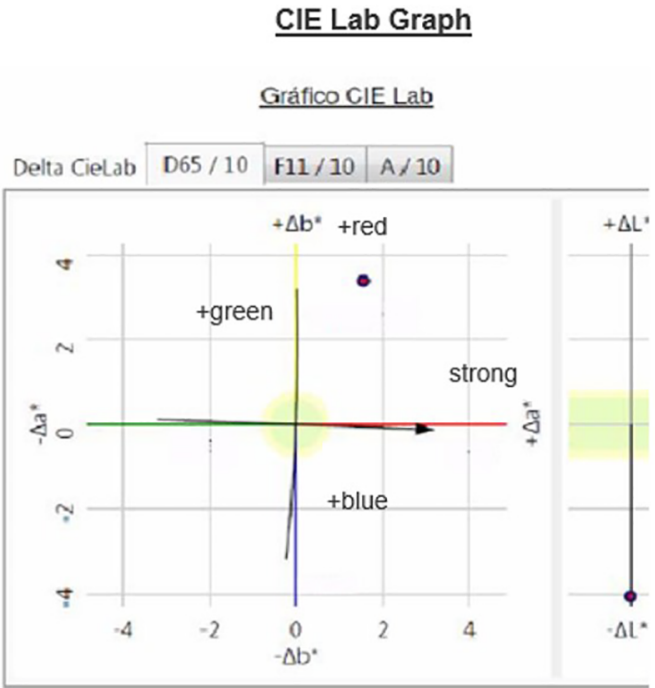

(c)

(c)

Figure 7. (a) Radar chart - color location, BEZAKTIV- S2G- BLUE. (b) Reflectance chart vs. wavelength, BEZAKTIV- S2G- BLUE. (c) Radar chart - color location, BEMACID E-TL-RED. (d) Reflectance chart vs. wavelength, BEMACID E-TL-RED.

Table 5. Result of the solidity degree - BEZAKTIV-S2G-BLUE dye.

\begin{tabular}{llll}
\hline Type of sample & \multicolumn{2}{c}{ Domestic washing - NBR -ISO-105-C01 } \\
\cline { 2 - 4 } & $\mathrm{AC}^{1}$ & $\mathrm{TC}^{2}$ & $4-5$ \\
\hline Untreated - A & $4-5$ & $4-5$ & \\
\hline Plasma-treated - B & $4-5$ & &
\end{tabular}

Table 6. Result of the solidity degree - BEMACID E-TL-RED dye.

\begin{tabular}{|c|c|c|}
\hline \multirow[t]{2}{*}{ Type of sample } & \multicolumn{2}{|c|}{ Domestic washing - NBR -ISO-105-C01 } \\
\hline & $\mathrm{AC}^{3}$ & $\mathrm{TC}^{4}$ \\
\hline Untreated - A & 4 & 2 \\
\hline Plasma-treated - B & 4 & $1-2$ \\
\hline
\end{tabular}




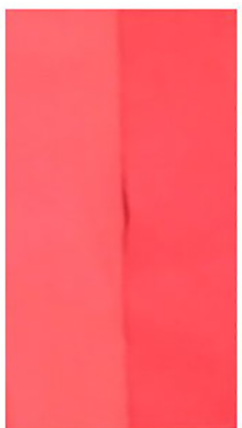

(a)

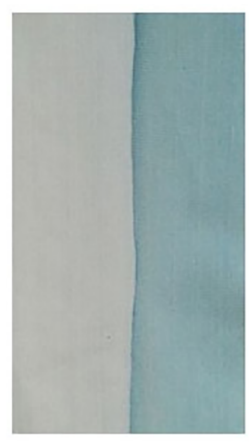

(b)
Figure 8. Untreated and plasma treated samples dyed with acid dye (a) BEMACID E-TL-RED; (b) BEZAKTIV- S2G- BLUE.

\section{Conclusion}

The chemical, structural and morphological characteristics of low-temperature plasma-treated PA-6.6 knitted fabric were investigated. It was found a significant reduction of the contact angle comparing the plasma-treated and non-treated fabric. The transmittance value of the groups corresponding to $\mathrm{C}-\mathrm{H}, \mathrm{N}-\mathrm{H}$, and $\mathrm{N}-\mathrm{O}$ was increased. This may explain the increase in the coloring strength for the plasma-treated samples when dyed with reactive and acid dyes in polyamide 6.6 knitted fabrics. Finally, by using the plasma treatment, a better fixation of dye was observed. Dyeing with a basic and acid dye caused the dyeability to increase for plasmatreated samples compared with the untreated sample. This analysis was based on color strength and solidity tests.

\section{Acknowledgments}

We acknowledge the financial support of FAPESP (grant $n^{\circ}$ 2015/23315-2), CNPq, CAPES, and SENAI (grant $n^{\circ}$ 2019/8907).

\section{References}

1. Francisco DL, Paiva LB, Aldeia W. Advances in Polyamide Nanocomposites: A Review. Polymer Composites. 2018;40(3):851870. DOI: https://doi.org/10.1002/pc.24837

2. Wavhal SD, Balasubramanya RH. Role of Biotechnology in the Treatment of Polyester Fabric. Indian Journal of Microbiology. 2011 Jun;51(2):117-123. DOI: https://doi.org/10.1007/s12088$011-0163-9$

3. Sayed U, Dabhi P. Finishing of textiles with fluorocarbons. In: Williams J, editor. Waterproof and Water Repellent Textiles and Clothing. Cambridge: Woodhead Publishing; 2014. p. 139-152. DOI: https://doi.org/10.1016/B978-0-08101212-3.00006-X

4. Morent R, Geyter N, Verschuren J, Clerck K, Kiekens P, Leys C. Non-thermal plasma treatment of textiles. Surface and Coatings Technology. 2008;202(14):3427-3449. DOI: https:// doi.org/10.1016/j.surfcoat.2007.12.027
5. Caiazzo F, Canonico P, Nigro R, Tagliaferri V. Electrode discharge for plasma surface treatment of polymeric materials. Journal of Materials Processing Technology. 1996;58(1):96-99. DOI: https://doi.org/10.1016/0924-0136(95)02112-4

6. Mandolfino C, Lertora E, Gambaro C. Influence of cold plasma treatment parameters on the mechanical properties of polyamide homogeneous bonded joints. Surface and Coatings Technology. 2017;313:222-229. DOI: https://doi.org/10.1016/j.surfcoat.2017.01.071

7. Lv J, Zhou Q, Zhi T, Gao D, Wang C. Environmentally friendly surface modification of polyethylene terephthalate (PET) fabric by low-temperature oxygen plasma and carboxymethyl chitosan. Journal of Cleaner Production. 2016;118:187-196. DOI: https://doi.org/10.1016/j.jclepro.2016.01.058

8. Urbaniak-Domagala W, Krucinska I, Wrzosek H, Komisarczyk, Chrzanowska O. Plasma modification of polylactide nonwovens for dressing and sanitary applications. Textile Research Journal. 2015;86(1):72-85. DOI: https://doi.org/10.1177/0040517515581586

9. Oliveira FR, Steffens F, Holanda PSB, Nascimento JHO, Matsui KN, Souto AP. Physical, Chemical and Morphological Characterization of Polyamide Fabrics Treated with Plasma Discharge. Materials Research. 2017;20(Suppl 2):60-68. DOI: https://doi.org/10.1590/1980-5373-MR-2016-1032

10. Xu W, Liu X. Surface modification of polyester fabric by corona discharge irradiation. European Polymer Journal. 2003;39(1):199202. DOI: https://doi.org/10.1016/S0014-3057(02)00169-6

11. Morent R, Geyter N, Leys C, Gengembre L, Payen E. Surface Modification of Non-woven Textiles using a Dielectric Barrier Discharge Operating in Air, Helium, and Argon at Medium Pressure. Textile Research Journal. 2007;77(7):471-488. DOI: https://doi.org/10.1177/0040517507080616

12. Ahmed HM, Ahmed KA, Mashaly HM, El-Halwagy AA. Treatment of Cotton Fabric with Dielectric Barrier Discharge (DBD) Plasma and Printing with Cochineal Natural Dye. Indian Journal of Science and Technology. 2017;10(10):1-10. DOI: https://doi.org/10.17485/ijst/2017/v10i10/100973

13. Van Deynse A, Cools P, Leys C, Geyter N, Morent R. Surface activation of polyethylene with an argon atmospheric pressure plasma jet: Influence of applied power and flow rate. Applied Surface Science. 2015;328:269-278. DOI: https://doi.org/10.1016/j.apsusc.2014.12.075

14. Kan CW, Man WS. Parametric Study of Effects of Atmospheric Pressure Plasma Treatment on the Wettability of Cotton Fabric. Polymers. 2018;10(3):233. DOI: https://doi.org/10.3390/polym10030233

15. Kale KH, Palaskar S. Atmospheric pressure plasma polymerization of hexamethyldisiloxane for imparting water repellency to cotton fabric. Textile Research Journal. 2011;81(6):608-620. DOI: https://doi.org/10.1177/0040517510385176

16. Souto AP, Oliveira FR, Carneiro N. Polyamide 6.6 Modified by DBD Plasma Treatment for Anionic Dyeing Processes. London: IntechOpen; 2011. Available from: https://www.intechopen. com/books/textile-dyeing/polyamide-6-6-modified-by-dbdplasma-treatment-for-anionic-dyeing-processes

17. Yip J, Chan K, Sin KM, Lau KS. Study of physicochemical surface treatments on dyeing properties of polyamides. Part 2: Effect of UV excimer laser irradiation. Color Technol. 2006;118(1):3134. DOI: https://doi.org/10.1111/j.1478-4408.2002.tb00134.x 
18. Zhang J, Zhou Z, Ye T, Xu Z, Xia W. Corona inducing dielectric barrier discharge. [access in 2018 oct 17]. In: https://www. researchgate.net/publication/266171545_Corona_inducing_ dielectric_barrier_discharge

19. Feitor MC, Alves Junior C, Bezerra CM, Sousa RRM, Costa THC. Evaluation of Aging in Air of Poly (Ethylene Terephthalate) in Oxygen Plasma. Materials Research. 2015;18(5):891-896. DOI: https://doi.org/10.1590/15161439.305814
20. Zarshenas K, Raisi A, Aroujalian A. Surface modification of polyamide composite membranes by corona air plasma for gas separation applications. RSC Advances. 2015;5(25): 19760-72. DOI: https://doi.org/10.1039/c4ra15547e

21. Al-Balakocy NG, El-Ola A. Effect of Surface Activation of Nylon-6 Fabrics by Plasma and Grafting With vinyl Monomers on Its Functional Finishing With $\mathrm{TiO}_{2}$ Nanoparticles. Journal of Applied Sciences Research. 2013;9(3):1743-1753. DOI: https://doi.org/10.13140/RG.2.1.4426.3440 